\title{
РЕЗУЛЬТАТЫ ХИРУРГИЧЕСКОГО ЛЕЧЕНИЯ ПАЦИЕНТОК С ПЕРВИЧНЫМ РАКОМ ГРУДНОЙ ЖЕЛЕЗЫ
}

\author{
Макаров В. В., д. мед. н., профессор, профессор кафедры хирургии № 1 Харьковского \\ национального медицинского университета, Украина; \\ Цивенко А. И., д. мед. н., профессор, профессор кафедры хирургических болезней Харьковского \\ национального университета имени В. Н. Каразина, Украина; \\ Королевская А. Ю., ассистент кафедры хирургии № 1 Харьковского национального \\ медицинского университета, Украина.
}

DOI: https://doi.org/10.31435/rsglobal_ws/31072019/6590

\section{ARTICLE INFO}

Received: 21 May 2019

Accepted: 13 July 2019

Published: 31 July 2019

\section{KEYWORDS}

breast cancer,

mastectomy.

\begin{abstract}
The treatment results of 172 patients with breast cancer, who underwent radical surgery on the breast, were analyzed. During the last 4 years, the implementation of combined surgical interventions - radical surgery with removal of the tumor with D2 lymphnode dissection and the simultaneous installation of a silicone implant (in 17 patients $-17.4 \%$ ) takes attention. In most cases, the early postoperative period proceeded safely. During the early postoperative period, complications occurred in $30(17.4 \%)$ patients: long postoperative lymphorrhea - $25(14.5 \%)$ cases, which in $6(3.6 \%)$ patients leaded to the development of seroma, and in two $(1.2 \%)$ of them - suppuration of the postoperative wound. Diastasis of wound edges was noted in $4(2.3 \%)$ patients. In $1(0.6 \%)$ case, bleeding was observed on the first day after surgery. Postoperative mortality rate was $0 \% .10(5.8 \%)$ patients were admitted for the surgery during the period from 1 to 3 years after the primary radical surgery due to a local recurrence of breast cancer. Despite the arsenal of modern diagnostic, anesthetic and surgical support, the issue of postoperative complications prevention and the disease recurrence prevention of the patients with breast cancer remains relevant.
\end{abstract}

Citation: Макаров В. В., Цивенко А. И., Королевская А. Ю. (2019) Rezul'taty Hirurgicheskogo Lecheniya Pacientok s Pervichnym Rakom Grudnoj Zhelezy. World Science. 7(47), Vol.1. doi: 10.31435/rsglobal_ws/31072019/6590

Copyright: (C) 2019 Макаров В. В., Цивенко А. И., Королевская А. Ю. This is an open-access article distributed under the terms of the Creative Commons Attribution License (CC BY). The use, distribution or reproduction in other forums is permitted, provided the original author(s) or licensor are credited and that the original publication in this journal is cited, in accordance with accepted academic practice. No use, distribution or reproduction is permitted which does not comply with these terms.

Вступление. Статистика ВОЗ показывает, что рак груди является наиболее распространенным видом рака во всем мире. В Украине рак молочной железы тоже лидирует среди женских онкологических заболеваний. По данным Института рака, каждая 7-8 женщина имеет проблемы с грудными железами, но к врачам обращается слишком поздно: при первом осмотре у четверти женщин обнаруживают метастатические стадии болезни, которые лечить очень трудно. Изменить ситуацию поможет раннее выявление болезни, ведь на 1 стадии рак груди излечивается в 95\% женщин $[1,2,3]$.

По данным Национального канцер-реестра Украины, на конец 2016 от рака груди страдало почти 138000 украинских женщтн. Ранние стадии рака (I-II) диагностируются в 76\% случаев и почти четверть пациентов обращаются к медикам на запущенных стадиях [1].

За последние 5 лет показатель заболеваемости вырос почти на 6\%. Вместе с тем, показатель смертности за тот же период уменьшился на 6\%. Однако смертность от рака груди все еще лидирует в структуре смертей от злокачественных опухолей $(20 \%)[1,2,3]$. 
Статистика говорит о том, что за последние 100 лет по уровню заболеваемости и смертности в мире онкопатология переместилась с десятого места на второе, уступая лишь болезням сердечно-сосудистой системы. По данным ВОЗ, каждый год вновь заболевают 10 млн человек. Как утверждает ВОЗ, смертность от рака до 2030 года возрастет на 45\%, по сравнению с уровнем 2007 года [1, 2, 3].

Украина на втором месте в Европе по темпам распространения рака. Злокачественные новообразования поражают в Украине каждого каждую шестую женщину [1].

Онкологическая заболеваемость стабильно возрастает на 2,6-3\% в год, и рак продолжает «молодеть». Демографическая картина заболеваемости по данным Национального института рака. Среди женщин в возрастной группе 30-74 лет наибольший удельный вес имеют злокачественные новообразования молочной железы [1].

Основными причинами смерти у женщин являются: злокачественные новообразования молочной железы, желудка, ободочной кишки, прямой кишки, яичников, шейки матки - 57,6\% [1].

За последние пять лет удельный вес основных нозологических форм злокачественных новообразований в структуре смертности практически не изменился. Косвенно это свидетельствует об отсутствии эффективных профилактических мер [1].

Как свидетельствует статистика, на 1 стадии рак груди излечивается в 95\% женщин, на 2 стадии в $80 \%$, а на 3 стадии $-50 \%[1,2,3]$.

Материалы и методы. Проведен ретроспективный анализ результатов хирургического лечения 172 пациенток с раком молочной железы с 2005 по 2019 годы, которым были выполнены радикальные оперативные вмешательства на грудной железе. Преобладали пациентки трудоспособного возраста, что обусловливает социальную значимость данной проблемы. Средний возраст составил 44,7 лет. Мужчин среди пациентов в данном исследовании не было.

Преобладали пациентки со II и III стадиями онкологического заболевания. Это указывает на необходимость улучшения диагностики данного заболевания на этапах первичного звена оказания медицинской помощи. Следует отметить, что на современном этапе отмечается поступление пациентки на радикальное лечение на II стадии рака молочной железы, что, возможно, непосредственно связано с активной пропагандой самообследования грудных желез женщиной.

Результаты и обсуждение. Анализируя результаты, отмечается превалирование локализации опухоли в наружных квандрантах. Наиболее частой локализацией опухолевого процесса у пациенток был верхненаружный квандрант - 48,3\% случаев. Во всех случаях отмечается односторонняя локализация онкологического процесса.

Только у 8 человек $(4,8 \%$ от всех больных) не было обнаружено сопутствующей патологии. Количество и тяжесть сопутствующей патологии увеличивались прямо пропорционально возрасту пациентов. Это снижало функционально-компенсаторные возможности организма, требовало коррекции в предоперационном периоде, влияло на течение послеоперационного периода. У 60 (34,8\%) пациенток отмечались заболевания со сторны сердечно-сосудистой системы, у 44 (25,6\%) ранее был установлен диагноз сахарного диабета. Ожирением страдали 22 (13,2\%) пациентки. У 10 (6\%) пациенток верифицировано две и более сопутствующих патологии.

Патогистоморфологическая верификация онкологической природы заболевания у пациенток с раком молочной железы была произведена на дооперационном этапе при помощи пункционной трепан-биопсии под контролем УЗИ (таблица 1).

Таблица 1. Патогистоморфологический тип опухоли

\begin{tabular}{|c|c|c|}
\hline Патогистоморфологический тип опухоли & $\mathrm{n}$ & $\%$ \\
\hline Аденокистозный рак & 2 & 1,2 \\
\hline Плоскоклеточный рак & 2 & 1,2 \\
\hline Скиррозный рак & 2 & 1,2 \\
\hline Метапластический рак & 6 & 3,5 \\
\hline Папилярный рак & 6 & 3,5 \\
\hline Слизистая аденокарцинома & 8 & 4,7 \\
\hline Медулярный рак & 10 & 5,8 \\
\hline Инфильтративный дольковый рак & 44 & 25,6 \\
\hline Инфильтративный протоковый рак & 92 & 53,5 \\
\hline
\end{tabular}


Данное исследование является наиболее информативным методом диагностики и подтверждения рака грудной железы. Согласно данным таблицы, более чем в половине случаев у пациенток был инфильтративный протоковый рак.

После предоперационной подготовки в плановом порядке пациенткам было выполнено радикальное оперативное вмешательство (Таблица 2).

Таблица 2. Виды оперативных вмешательств у пациенток

\begin{tabular}{|l|c|c|}
\hline Оперативное вмешательство & $\mathrm{n}$ & $\%$ \\
\hline Радикальная мастэктомия по Маддену & 99 & 57,6 \\
\hline Радикальная мастэктомия по Пейти-Дайсену & 30 & 17,4 \\
\hline Радикальная мастэктомия по Холстеду-Майеру & 10 & 5,8 \\
\hline $\begin{array}{l}\text { Секторальная резекция с лимфодиссекцией и одномоментной } \\
\text { установкой силиконового импланта }\end{array}$ & 30 & 17,4 \\
\hline Атипичная резекция с лимфодиссекцией & 3 & 1,7 \\
\hline
\end{tabular}

Радикальные оперативные вмешательства с лимфодиссекцией Д2 выполнены у всех пациенток. В последние 4 года обращает на себя внимание выполнение комбинированных оперативных вмешательств - радикального удаления опухоли с лимфодиссекцией Д2 и одновременной установкой силиконового импланта (у 30 пациенток - 17,4\%).

В большинстве случаев ранний послеоперационный период протекал благополучно.

В раннем послеоперационном периоде осложнения возникли у $30(17,4 \%)$ пациенток. Наибольший вес среди осложнений занимала длительная (продолжительностью более месяца) послеоперационная лимфоррея - 25 (14,5\%) случаев, что у $6(3,6 \%)$ пациенток сопровождалось развитием сером, и у двух $(1,2 \%)$ из них - нагноением послеоперационной раны.

Несостоятельность (диастаз) краев раны отмечен в 4 (2,3\%) пациенток.

У одной $(0,6 \%)$ пациентки наблюдалось кровотечение в первые сутки после операции.

Все пациентки выжили.

Послеоперационная летальность составила $0 \%$.

На повторные оперативные вмешательства в сроки от 1 до 3-х лет после первичной радикальной операции поступили $10(5,8 \%)$ пациенток в связи с локальным рецидивом рака грудной железы.

Выводы. Несмотря на арсенал современного диагностического, анестезиологического и хирургического обеспечения остается актуальным вопрос профилактики послеоперационных осложнений и профилактики рецидива заболевания у пациенток с раком грудной железы.

\section{ЛИТЕРАТУРА}

1. Рак в Україні. Бюлетень Національного канцер-реєстру. 2017-2018. № 20. С.46-47

2. Seroma formation after breast cancer surgery: incidence and predicting factors [ P. A.Woodworth, M. F. McBoyle, S. D. Helmer, R. L. Beamer] // The American Journal of Surgery. - 2010. - №4 - - P. 444-450.

3. Seenivasagam R. K. Prevention of Seroma Formation after Axillary Dissection-A Comparative Randomized Clinical Trial of Three Methods / R. K. Seenivasagam, V. Gupta, G. Singh. // The Breast Journal. - 2013. - №5. - P. 478-484. 